\title{
REGULAÇÃO GÊNICA DA VIA AMPK PELO EXERCÍCIO FÍSICO: REVISÃO SISTEMÁTICA E ANÁLISE IN SILICO
}

\author{
AMPK PATHWAY GENEREGULATION BY PHYSICAL EXERCISE:SYSTEMATICREVIEW AND \\ INSILICO ANALYSIS \\ REGULACIÓN GÉNICA DE LA VIIAAMPKPOR EL EJERCICIO FISICO: REVISIÓN SISTEMÁTICA \\ Y ANÁLISIS INSILICO
}

Artigo de ReVisäo Sistemática

SYSTEMATIC REVIEW ARTICLE

ARTICULO de REVISIÓN SISTEMÁtICA

Christina Pacheco

(Geneticista)

Luiz Henrique Pontes dos Santos ${ }^{1}$ (Biólogo)

Juliana Osório Alves

(Profissional de Educação Física)

Adriano Nogueira de Queiroz ${ }^{2}$

(Médico)

Paula Matias Soares'

(Profissional de Educação Física)

Vânia Marilande Ceccatto'

(Bióloga)

1. Universidade Estadual do Ceará, Instituto Superior de Ciências Biomédicas; Fortaleza, CE, Brasil. 2. Hospital e Maternidade José Martiniano de Alencar (HMJMA), Fortaleza,

CE, Brasil.

\section{Correspondência:}

Vânia Marilande Ceccatto Universidade Estadual do Ceará, Instituto Superior de Ciências Biomédicas, Laboratório de Bioquímica e Expressão Gênica. Rua Dr. Silas Munguba, 1700, Campus do Itaperi, Fortaleza, CE, Brasil. 60.714903.

vania.ceccatto@uece.br

\section{RESUMO}

Introdução: Novos estudos de regulação gênica do exercício físico por meio de técnicas pós-genômicas em ensaios de resistência (endurance) e força caracterizam a transcriptômica do exercício físico. Entre os genes afetados, destacamos a via da proteína quinase ativada por AMP (AMPK), cuja ativação ocorre durante o exercício como resultado das alterações dos níveis de fosfato energético da fibra muscular. Objetivo: Avaliar a via de sinalização da AMPK por revisão sistemática da expressão de genes e análise in silico. Método: Foi efetuada uma revisão sistemática para avaliar a regulação gênica da via de sinalização AMPK, caracterizando os genes estudados na literatura, as variações de regulação obtidas, na forma de fold change e tipos de exercício usados. Resultados: A via de sinalização AMPK mostrou 133 genes no repositório KEGG (Kyoto Encyclopedia of Genes and Genomes), os quais foram confrontados com a revisão sistemática da literatura, totalizando 65 genes. Dezessete genes apresentaram UR e 24 mostraram DR com relação ao seu respectivo controle. Além destes, 20 genes estavam presentes nos trabalhos, apresentando tanto UR e DR e quatro genes não apresentaram dados de regulação. Verificou-se regulação específica em função do tipo de exercício efetuado. Discussão: Dos 133 genes da via AMPK, 48,8\% foram amostrados nos trabalhos revisados, indicando que uma parte significativa da via é regulada pelo exercício. O estudo apresentou a regulação gênica básica de dois mecanismos para a recuperação energética, a biogênese mitocondrial e o bloqueio da gliconeogênese. Conclusão: Este trabalho mostrou que o exercício atua ativamente na via de sinalização da AMPK, na importância da regulação via PGC-1a e no papel de outros genes, regulando a expressão de mais da metade dos genes amostrados.

Descritores: AMP cíclico; transcrição genética; exercício.

\section{ABSTRACT}

Introduction: New studies of gene regulation by physical exercise through post-genomic techniques in endurance and strength tests characterize the physical exercise transcriptomics. Among the affected genes, we highlight the AMP-activated protein kinase (AMPK) pathway, the activation of which occurs during exercise because of changes in muscle fiber energetic phosphate levels. Objective: To evaluate the AMPK signaling pathway by systematic review of gene expression and in silico analysis. Method: A systematic review was performed in order to assess the gene regulation of AMPK signaling pathway, characterizing the genes studied in the literature, regulation variations obtained in the form of fold change, and types of exercise performed. Results: The AMPK signaling pathway showed 133 genes in the KEGG repository (Kyoto Encyclopedia of Genes and Genomes), which were compared with the systematic review of the literature, totaling 65 genes. Seventeen genes presented UR and 24 showed DR in relation to their respective control. In addition to these, 20 genes were present in the literature, presenting both UR and DR and four genes showed no regulatory data. Specific regulation was verified according to the type of exercises performed. Discussion: Of the 133 genes of the AMPK pathway, 48.8\% were sampled in the revised studies indicating that a significant part of the pathway is regulated by exercise. The study presented the basic gene regulation of two mechanisms for energy recovery, mitochondrial biogenesis, and gluconeogenesis blockade. Conclusion: This work showed that the exercise actively works in the AMPK signaling pathway, in the importance of regulation via PGC-1a and in the role of other genes, regulating the expression of more than half of the genes sampled.

Keywords: cyclic AMP; transcription, genetic; exercise.

\section{RESUMEN}

Introducción: Nuevos estudios de regulación génica del ejercicio físico por medio de técnicas pos-genómicas en ensayos de resistencia (endurance) y fuerza caracterizan la transcriptómica del ejercicio físico. Entre los genes afectados, destacamos la vía de la proteína quinasa activada por AMP (AMPK), cuya activación ocurre durante el ejercicio como resultado de las alteraciones de los niveles de fosfato energético de la fibra muscular. Objetivo: Evaluar la vía de señalización AMPK por revisión sistemática de la expresión de genes y análisis in silico. Método: Se ha efectuado una revisión para evaluar la regulación génica de la vía de señalización AMPK, caracterizando los genes estudiados en la literatura, las variaciones de regulación obtenidas en forma de fold change y tipos de ejercicios utilizados. 
Resultados: La vía de señalización AMPK mostró 133 genes en el repositorio KEGG (Kyoto Encyclopedia of Genes and Genomes), los cuales fueran confrontados con la revisión sistemática de la literatura, totalizando 65 genes. Diecisiete genes presentaron UR y 24 mostraron DR con respecto a su respectivo control. Además de estos, 20 genes estaban presentes en los trabajos, presentando tanto URy DRy cuatro genes no presentaron dados de regulación. Se observó una regulación específica en función del tipo de ejercicio efectuado. Discusión: De los 133 genes de la vía AMPK, $48,8 \%$ fueron muestreados en los trabajos revisados, indicando que una parte significativa de la vía es regulada por el ejercicio. El estudio presentó la regulación génica básica de dos mecanismos para la recuperación energética, la biogénesis mitocondrial y el bloqueo de la gluconeogénesis. Conclusión: Este trabajo mostró que el ejercicio actúa activamente en la vía de señalización AMPK, en la importancia de la regulación vía factor PGC-1a y en el papel de otros genes, regulando la expresión de más de la mitad de los genes muestreados.

Descriptores: AMP cíclico; transcripción genética; ejercicio.

\section{INTRODUÇÃO}

A fisiologia molecular do exercício físico nos últimos tempos vem se beneficiando de estudos pós-genômicos, relativos à expressão gênica pós-exercício, gerando imensas listas de genes diferencialmente expressos ligados ao exercício físico, em diversos tecidos do corpo humano, em ensaios com exercício de endurance e de força, avaliando quais genes e em que valor, são transcritos em mRNA, após o estímulo físico. A expressão gênica diferencial pode ser realizada por diversas técnicas moleculares, como PCR quantitativo (qPCR), microarray ou sequenciamento do RNA total (RNA-Seq) $)^{1,2}$

As diferentes técnicas variam em escala de utilização, na necessidade de conhecimentos prévios e no custo. qPCR avalia a expressão diferencial gene a gene, comparando a mudança nos níveis de expressão com genes controles endógenos, genes estes que se expressam de forma constante ${ }^{3}$. Microarrayé um experimento em larga escala, com milhares de sondas de oligonucleotídeos, para detectar concentrações diferentes de transcritos nas amostras. RNA-Seq é uma técnica moderna de biologia molecular que usa sequenciamento de segunda geração para avaliação qualitativa dos transcritos e quantificação da expressão gênica diferencia|l,5.

Os ensaios de expressão gênica diferencial por qPCR e microarray necessitam de conhecimentos prévios, de genes-alvo para detectar diferenças na expressão, o que não é necessário para o RNA-Seq. Os experimentos com microarray e RNA-Seq validam alguns de seus resultados com qPCR. Todas essas técnicas de detecção de expressão diferencial têm características distintas, mas seus resultados podem ser comparados em termos de quanto a expressão destes genes variaram com relação a taxa original, ou em comparação a um padrão de expressão basal. A medida de taxa de expressão gênica usualmente utilizada é o valor de expressão relativo, ou "fold change"- $F C^{6}$ o qual caracteriza a expressão gênica relativa positiva ou negativa (valores relativos positivos Up- ou negativos - Down-regulation) (UR ou DR). Estas avaliações são feitas, no caso do exercício físico, com padrões de controle com indivíduos sedentários ou o não-exercício.

A avaliação funcional dos conjuntos gênicos e de sua variação no exercício envolve o trabalho de complementar a notação gênica com dados funcionais, através de bancos de dados e ferramentas virtuais que possibilitam desenvolver e determinar quais grupos gênicos estão envolvidos na regulação e sinalização caracterizando as vias moleculares principais e sua caracterização?.

Dentre as vias potenciais de avaliação dentro do contexto genômico-funcional, a via de sinalização da proteína AMPK no exercício físico é bem conhecida na literatura especializada ${ }^{8,9}$. A proteína quinase ativada por AMP (AMPK) é uma molécula sinalizadora que é ativada durante o exercício como resultado das alterações que ocorrem nos níveis de fosfato energético da fibra muscular. Essa molécula regula numerosas vias energéticas nos músculos. Uma vez ativada, a AMPK, leva a uma inibição das vias metabólicas que consomem energia como a síntese de glicogênio, ou aumento na produção de fatores que ajudam a aumentar a produção de ATP, como a ativação da biogênese mitocondrial.10-12

Assim, a ciência do exercício físico evolui, porém ainda há muito a caminhar, tendo em vista a velocidade dos estudos científicos na área molecular, incorporando novos paradigmas que podem ampliar a visão dos processos fisiológicos e moleculares envolvidos. Neste contexto, a expressão gênica da via de sinalização da proteína AMPK induzida pelo exercício, pode ser caracterizada incluindo possíveis rotas metabólicas de ativação, graças a estudos de investigação das alterações pós-genômicas induzidos pelo exercício. Numa visão molecular da regulação gênica o trabalho destes autores pode ser chamado de caracterização de natureza "a posteriori", no sentido de que as análises foram feitas pós-indução pelo exercício.

Em suma, este trabalho procedeu a uma revisão sistemática de literatura em língua inglesa, analisando trabalhos de autores que se dedicaram a verificar quais e quanto, genes foram expressos, ligados ao exercício de endurance ou resistido, dentro das três técnicas pós-genômicas citadas. Os dados obtidos destes autores foram tabelados e analisados por diversas ferramentas in silico. Focou-se na presença e no quantitativo da expressão de genes da via AMPK tendo em vista sua importância para o estudo comparativo do exercício.

\section{METODOLOGIA}

\section{Revisão sistemática}

Genes expressos na forma de RNA, ligados ao exercício físico de endurance (E) e resistido (R), em humanos foram catalogados de artigos científicos, na língua inglesa, através de uma revisão sistemática (período das publicações de 2003 a 2015) utilizando os bancos de dados PubMed, PubMedCentral (PMC), repositórios digitais de uso livre de artigos científicos ligados ao National Center for Biotechnology Information - USA e Google Scholar, introduzindo os seguintes termos de busca: 'exercise', 'fitness', 'physical activity', 'genetics' e 'gene expression"13. As publicações obtidas foram pesquisadas manualmente em busca por referências suplementares, totalizando 58 artigos. Como critérios de elegibilidade, foram selecionados artigos que utilizaram as técnicas de avaliação de expressão gênica (também chamadas pós-genômicas) já citadas: microarrays, RNA-Seq, qPCR ou RT-PCR. Os seguintes dados foram coletados dos estudos: símbolo do gene, nome do gene, protocolo de exercício, dados de expressão diferencial, significância estatística e referência bibliográfica.

\section{ANÁLISE IN SILICO}

A via da AMPK, contendo 133 genes, localizada na base KEGG (Kyoto Encyclopedia of Genes and Genomes ${ }^{14}$, foi usada como padrão deste 
trabalho. (Endereço virtual da via: http://www.genome.jp/kegg-bin/ show_pathway?map=hsa04152\&showdescription=show).

A meta-análise in silico consistiu na confrontação dos genes obtidos na revisão sistemática com a citada via AMPK padrão, encontrada na base KEGG (133 genes), encontrando-se 65 genes nesta interface, os quais foram posteriormente tabelados, conforme detalhado abaixo. Para a obtenção desta interface - genes obtidos na revisão sistemática x base KEGG foram utilizadas ferramentas de busca online citadas adiante. 0 conjunto de genes (65) foi analisado quanto à resposta transcricional, tanto para os diferentes tipos de exercício quanto sua maior ou menor inserção na via de sinalização da AMPK.

Como padronização, os estudos foram baseados na versão GRCh38 do Projeto Genoma Humano (National Center for Biotechnology Information - ww.ncbi.nlm.nih.gov) e as buscas e anotações gênicas foram obtidas no banco de dados e também ferramentas de bioinformática do ENSEMBL(http://www.ensembl.org/info/docs/tools/index.html).
Para organização e sistematização, os 65 genes da interface - revisão sistemática x base KEGG foram tabelados e coletadas as seguintes informações, a partir dos dados fornecidos pelos autores: nomes de genes e símbolos, o tipo de regulação: UR ou DR e o valor de fold-change, o

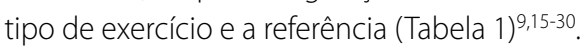

Além das informações próprias da base KEGG, utilizou-se a ferramenta de busca e análise da basede dados STRING para avaliar as interações moleculares (String-db.org, acesso em junho/2016) ${ }^{31}$, com os seguintes parâmetros: análise restrita à espécie Homo sapiens e no campo"fontes de interação": bancos de dados, co-expressão, co-ocorrência, fusão gênica, vizinhança e mineração de textos. STRING é uma base de dados com ferramentas para interação e predição de interações proteina-proteína, a qual fornece um diagrama ou grafo de interação entre moléculas ou partículas.

Os valores de fold-change, juntamente com as informações gerais coletadas da via AMPK da base KEGG e STRING, entre outras informações da literatura permitiram a produção das Figuras 1 e 2 .

Tabela 1. Lista de genes presentes na via da AMPK com regulação pelo exercício físico, regulação Up/Down (UR/DR), fold change, tipo de exercício e a referência.

\begin{tabular}{|c|c|c|c|c|}
\hline $\begin{array}{c}\text { Gene } \\
\text { (Símbolo original) }\end{array}$ & $\begin{array}{c}\text { Nome } \\
\text { (Nome original) }\end{array}$ & Fold Change & $\begin{array}{l}\text { Tipo de exer- } \\
\text { cício }\end{array}$ & Referência \\
\hline PPARGCIA & Peroxisome proliferator-activated receptor gamma, coactivator 1 alpha & $\begin{array}{r}10,0 \\
-1,01\end{array}$ & $\begin{array}{l}E \\
R\end{array}$ & 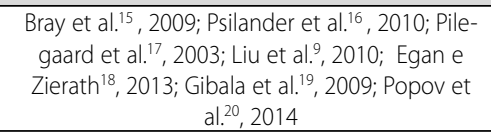 \\
\hline SCD & Stearoyl-CoAdesaturase (delta-9-desaturase) & 7,20 & $E$ & Timmons et al. ${ }^{21}, 2010$; Lindholm et al. ${ }^{22}, 2014$ \\
\hline PRKAG2 & Protein kinase, AMP-activated, gamma 2 non-catalytic subunit & 4,79 & $\begin{array}{l}E \\
R\end{array}$ & Liu et al. ${ }^{9}, 2010$; Lindholm et al.22, 2014 \\
\hline CCND1 & Cyclin D1 & 3,80 & $\begin{array}{l}E \\
R\end{array}$ & $\begin{array}{l}\text { Liu et al. }{ }^{9}, 2010 ; \text { Timmons et al..21, 2010; Lindholm } \\
\text { et al. }{ }^{22}, 2014\end{array}$ \\
\hline IRS2 & Insulin receptor substrate 2 & $\begin{array}{c}, 41 \\
-1,93\end{array}$ & $\begin{array}{l}E \\
R\end{array}$ & Liu et al. ${ }^{9}, 2010$; Lindholm et al. ${ }^{22}, 2014$ \\
\hline PDPK1 & 3-Phosphoinositide dependentproteinkinase 1 & $-2,27$ & $\begin{array}{l}E \\
R\end{array}$ & Stepto et al. ${ }^{23}, 2009$ \\
\hline PFKL & Phosphofructokinase, liver & 2,20 & E & Timmons et al.. ${ }^{21}, 2010$; Lindholm et al. ${ }^{22}, 2014$ \\
\hline$R A B 11 B$ & RAB11B, member RAS oncogene family & 1,80 & $\mathrm{E}$ & Timmons et al. ${ }^{21}, 2010$; Lindholm et al. ${ }^{22}, 2014$ \\
\hline FOXO1 & Forkhead box 01 & 1,80 & $\begin{array}{l}E \\
R\end{array}$ & Popov et al. ${ }^{20}, 2014$; Egan e Zierath ${ }^{18}, 2013$ \\
\hline LIPE & Lipase, hormone-sensitive & $\begin{array}{c}1,7 \\
-1,12 \\
\end{array}$ & $\begin{array}{l}E \\
R\end{array}$ & $\begin{array}{l}\text { Liu et al. }{ }^{9} \text {,2010; Timmons et al. }{ }^{21} \text {, 2010; Lindholm } \\
\text { et al. }{ }^{22}, 2014\end{array}$ \\
\hline MLYCD & Malonyl-CoAdecarboxylase & 1,65 & E & Lindholm et al.22, 2014 \\
\hline EIFAEBP1 & Eukaryotic translation initiation factor 4 E binding protein 1 & $-1,52$ & $\mathrm{R}$ & Liu et al. ${ }^{9}, 2010 ;$ \\
\hline PPARG & Peroxisomeproliferator-activated receptor gamma, coactivator 1 alpha & 1,50 & $\begin{array}{l}\mathrm{E} \\
\mathrm{R}\end{array}$ & $\begin{array}{c}\text { Bray et al.15, 2009; Egan e Zierath }{ }^{18}, 2013 \text {; Ruchat } \\
\text { et al..24, 2009; Lindholm et al..22, } 2014\end{array}$ \\
\hline CD36 & CD36 molecule (thrombospondin receptor) & $\begin{array}{r}1,50 \\
-1,15 \\
\end{array}$ & $\mathrm{E}$ & $\begin{array}{l}\text { Liu et al. }{ }^{9}, 2010 ; \text { Timmons et al..21, 2010; Lindholm } \\
\text { et al. }{ }^{22}, 2014\end{array}$ \\
\hline AKT3 & $V$-akt murine thymoma viral oncogene homolog 3 & 1,50 & $R$ & Timmons et al. ${ }^{21}, 2010 ;$; Lindholm et al. ${ }^{22}, 2014$ \\
\hline CPT1B & Carnitinepalmitoyltransferase $1 B$ (muscle) & $-1,49$ & $\mathrm{R}$ & Liu et al. ${ }^{9}, 2010$ \\
\hline CPT1A & Carnitine palmitoyltransferase $1 \mathrm{~A}$ (liver) & 1,49 & $E$ & Lindholm et al. $.^{22}, 2014$ \\
\hline PRKAG3 & Protein kinase, AMP-activated, gamma 3 non-catalytic subunit & $-1,47$ & $E$ & Timmons et al..21, 2010; Lindholm et al. ${ }^{22}, 2014$ \\
\hline CREB3L1 & CAMP responsive element binding protein 3-like 1 & 1,41 & $\mathrm{E}$ & Lindholm et al. ${ }^{22}, 2014$ \\
\hline IGFI & Insulin-like growth factor 1 (somatomedin C) & $\begin{array}{r}-1,30 \\
2,50 \\
\end{array}$ & $\mathrm{R}$ & $\begin{array}{c}\text { Bray et al. }{ }^{15}, 2009 ; \text { Liu et al. }{ }^{9}, 2010 ; \text { Timmons et } \\
\text { al. }{ }^{21}, 2010 ; \text {; Lindholm et al. }{ }^{22}, 2014\end{array}$ \\
\hline PRKAA2 & protein kinase, AMP-activated, alpha 2 catalytic subunit & $-1,29$ & $E$ & Lindholm et al. ${ }^{22}, 2014$ \\
\hline TSC1 & Tuberoussclerosis 1 & $-1,25$ & $\mathrm{R}$ & Liu et al. ${ }^{9}, 2010 ;$ : Lindholm et al. ${ }^{22}, 2014$ \\
\hline RPS6KB1 & Ribosomalprotein S6 kinase, 70kDa, polypeptide 1 & $-1,25$ & $\mathrm{R}$ & Liu et al. ${ }^{9}, 2010$; Lindholm et al. ${ }^{22}, 2014$ \\
\hline PFKFB3 & 6-phosphofructo-2-kinase/fructose-2,6-biphosphatase 3 & $\begin{array}{r}1,25 \\
-6,14 \\
\end{array}$ & $\mathrm{R}$ & Liu et al. ${ }^{9}, 2010$; Lindholm et al. ${ }^{22}, 2014$ \\
\hline CAB39 & Calciumbindingprotein 39-like & $-1,24$ & $E$ & Lindholm et al.22, 2014 \\
\hline IGFIR & Insulin-like growth factor 1 receptor & $-1,24$ & E & Lindholm et al..22, 2014 \\
\hline GYS1 & Glycogensynthase 1 (muscle) & $\begin{array}{r}1,24 \\
-1,17 \\
\end{array}$ & $\mathrm{R}$ & Bray et al. ${ }^{15}, 2009$; Liu et al. ${ }^{9}, 2010$; \\
\hline$P I K 3 C D$ & Phosphatidylinositol-4,5-bisphosphate 3-kinase, catalytic subunit delta & 1,24 & E & Lindholm et al. ${ }^{22}, 2014$ \\
\hline PFKFB2 & 6-phosphofructo-2-kinase/fructose-2,6-biphosphatase 2 & 1,22 & $\mathrm{E}$ & Lindholm et al. ${ }^{22}, 2014$ \\
\hline$P P P 2 R 3 A$ & Protein phosphatase 2, regulatory subunit $B^{\prime \prime}$ alpha & $-1,21$ & $E$ & Lindholm et al. 22,2014 \\
\hline FOXO3 & Forkhead box $\mathrm{O} 3$ & $\begin{array}{c}1,21 \\
-1,78 \\
\end{array}$ & $\mathrm{R}$ & $\begin{array}{c}\text { Liu et al. }{ }^{9}, 2010 \text {; Egan e Zierath }{ }^{18}, 2013 \text {; Lind- } \\
\text { holm et al.22, } 2014\end{array}$ \\
\hline CAB39L & Calciumbindingprotein 39-like & $-1,20$ & E & Lindholm et al..22, 2014 \\
\hline PFKM & Phosphofructokinase, muscle & $\begin{array}{r}1,18 \\
-1,12 \\
\end{array}$ & $\mathrm{R}$ & Bray et al. ${ }^{15}, 2009$; Liu et al. ${ }^{9}, 2010$ \\
\hline RHEB & Ras homolog enriched in brain & $\begin{array}{r}1,18 \\
-1,07 \\
\end{array}$ & $\mathrm{R}$ & Liu et al. ${ }^{9}, 2010 ;$ Lindholm et al.22, 2014 \\
\hline MAP3K7 & Mitogen-activated protein kinase kinasekinase 7 & $-1,17$ & E & Lindholm et al. ${ }^{22}, 2014$ \\
\hline CAMK2 & Calcium/calmodulin-dependent protein kinase kinase 2, beta & 1,17 & E & Lindholm et al. ${ }^{22}, 2014$ \\
\hline PIK3CA & Phosphatidylinositol-4,5-bisphosphate 3-kinase, catalytic subunit alpha & $-1,16$ & $E$ & Lindholm et al.22, 2014 \\
\hline
\end{tabular}




\begin{tabular}{|c|c|c|c|c|}
\hline $\begin{array}{c}\text { Gene } \\
\text { (Símbolo original) }\end{array}$ & $\begin{array}{c}\text { Nome } \\
\text { (Nome original) }\end{array}$ & Fold Change & $\begin{array}{l}\text { Tipo de exer- } \\
\text { cício }\end{array}$ & Referência \\
\hline PFKP & Phosphofructokinase, platelet & 1,16 & $E$ & Lindholm et al. ${ }^{22}, 2014$ \\
\hline TBC1D1 & TBC1 domain family, member 10A & $-1,15$ & $E$ & Lindholm et al. ${ }^{22}, 2014$ \\
\hline PIK3CB & Phosphatidylinositol-4,5-bisphosphate 3-kinase, catalytic subunit beta & $-1,14$ & $E$ & Lindholm et al. ${ }^{22}, 2014$ \\
\hline$P P P 2 R 3 B$ & Protein phosphatase 2 , regulatory subunit $B^{\prime \prime}$, beta & $-1,13$ & $E$ & Lindholm et al. ${ }^{22}, 2014$ \\
\hline PPP2R5A & Protein phosphatase 2, regulatory subunit $B^{\prime}$, alpha & $-1,13$ & $E$ & Lindholm et al. ${ }^{22}, 2014$ \\
\hline$A C A C A$ & Acetyl-CoA carboxylase alpha & 1,13 & $E$ & Lindholm et al. ${ }^{22}, 2014$ \\
\hline INSR & Insulin receptor & $-1,12$ & $E$ & Lindholm et al. ${ }^{22}, 2014$ \\
\hline RPS6KB2 & Ribosomalprotein S6 kinase, 70kDa, polypeptide 2 & $-1,12$ & $E$ & Lindholm et al. ${ }^{22}, 2014$ \\
\hline$A C A C B$ & Acetyl-CoA carboxylase beta & 1,12 & $E$ & Lindholm et al. ${ }^{22}, 2014$ \\
\hline PRKAB2 & Protein kinase, AMP-activated, beta 2 non-catalytic subunit & $-1,11$ & $E$ & Lindholm et al. ${ }^{22}, 2014$ \\
\hline ULK1 & unc-51 like autophagy activating kinase 1 & $-1,11$ & $E$ & Lindholm et al. ${ }^{22}, 2014$ \\
\hline RAB2A & RAB2A, member RAS oncogene family & $-1,10$ & $E$ & Lindholm et al. ${ }^{22}, 2014$ \\
\hline TSC2 & TSC22 domainfamily, member 3 & $\begin{array}{r}1,10 \\
-1,12 \\
\end{array}$ & E & Liu et al. ${ }^{9}, 2010$ \\
\hline SLC2A4 & Solutecarrierfamily 2 & $\begin{array}{r}1,08 \\
-1,34 \\
\end{array}$ & $\mathrm{R}$ & Liu et al. ${ }^{9}, 2010$ \\
\hline IRSI & Insulin receptor substrate 1 & $\begin{array}{r}1,07 \\
-1,54 \\
\end{array}$ & $\mathrm{R}$ & Liu et al. ${ }^{9}, 2010$ \\
\hline$E E F 2 K$ & Eukaryoticelongation factor-2 kinase & $\begin{array}{r}1,05 \\
-1,55 \\
\end{array}$ & $\begin{array}{l}\mathrm{E} \\
\mathrm{R}\end{array}$ & $\begin{array}{l}\text { Liu et al. }{ }^{9}, 2010 \text {; Timmons et al. }{ }^{21} \text {, 2010; Lindholm } \\
\text { et al. }{ }^{22}, 2014\end{array}$ \\
\hline mTOR & Late endosomal/lysosomal adaptor, MAPK and MTOR activator 5 & $\begin{array}{r}1,05 \\
-1,09 \\
\end{array}$ & $E$ & Liu et al. ${ }^{9}, 2010$ \\
\hline SREBF1 & Sterol regulatory element binding transcription factor 1 & $\begin{array}{r}1,03 \\
-1,49 \\
\end{array}$ & $\mathrm{R}$ & Liu et al. ${ }^{9}, 2010$ \\
\hline AKT1 & v-akt murine thymoma viral oncogene homolog 1 & $\begin{array}{r}1,01 \\
-1,45 \\
\end{array}$ & $\begin{array}{l}\mathrm{E} \\
\mathrm{R}\end{array}$ & $\begin{array}{l}\text { Liu et al. }{ }^{9}, 2010 \text {; Timmons et al. }{ }^{21}, 2010 ; \text {; Lindholm } \\
\text { et al. }{ }^{22}, 2014\end{array}$ \\
\hline AKT1S1 & AKT1 substrate 1 (proline-rich) & $\begin{array}{r}1,01 \\
-1,45 \\
\end{array}$ & $\mathrm{R}$ & Liu et al. ${ }^{9}, 2010$; \\
\hline CFTR & Cysticfibrosistransmembraneconductanceregulator & * & - & Bray et al. ${ }^{15}, 2009$ \\
\hline LEP & Leptin & * & $\begin{array}{l}E \\
R\end{array}$ & $\begin{array}{c}\text { Bray et al. }{ }^{15}, 2009 ; \text { Walsh et al. }{ }^{25}, 2012 \text {; Golbidi e } \\
\text { Laher }^{26}, 2014 \text {; Moran et al. }{ }^{27}, 2011 \text {. Kraemer e } \\
\text { Castracane }{ }^{28}, 2007\end{array}$ \\
\hline LEPR & Leptin receptor & * & $\mathrm{R}$ & $\begin{array}{c}\text { Bray et al. }{ }^{15}, 2009 ; \text { De Moor et al. }{ }^{29}, 2009 ; \text { Walsh } \\
\text { et al. }{ }^{25}, 2012\end{array}$ \\
\hline ADIPOR1 & Adiponectin receptor 1 & * & - & Bray et al. ${ }^{15}, 2009$ \\
\hline CREB1 & CAMP responsive element binding protein 1 & * & $E$ & Egan e Zierath $^{18}, 2013 ;$ \\
\hline SIRT1 & Sirtuin 1 & $*$ & $E$ & Egan e Zierath ${ }^{18}, 2013 ;$ \\
\hline PRKAA1 & Protein kinase, AMP-activated, alpha 1 catalytic subunit & * & $E$ & Gibala et al. ${ }^{19}, 2009$ \\
\hline PIK3R1 & Phosphoinositide-3-kinase, regulatorysubunit 1 & * & $\mathrm{R}$ & Radom-Aizik et al. ${ }^{30}, 2013$ \\
\hline
\end{tabular}

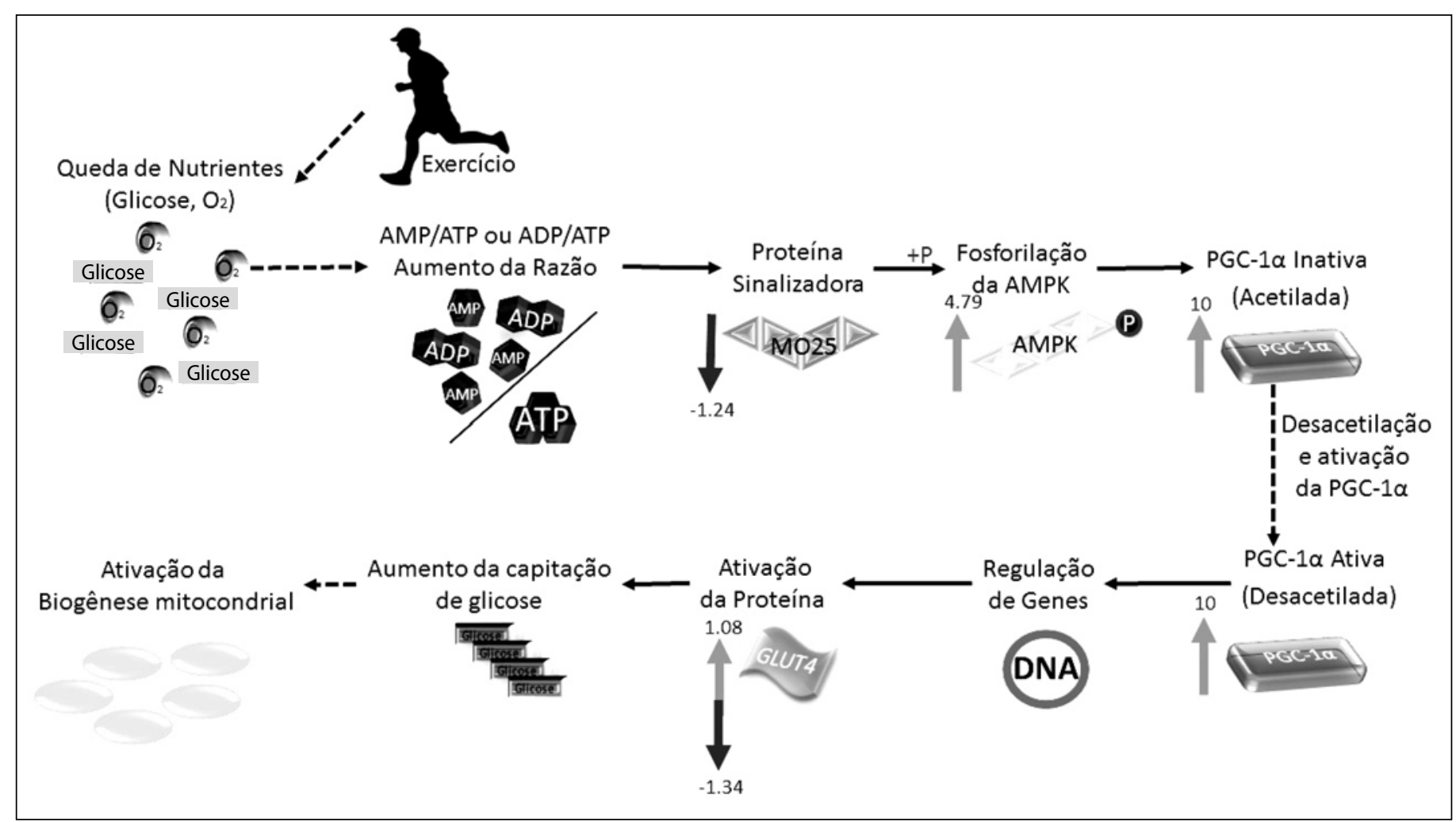

Figura 1. Rota de ativação da biogênese mitocondrial pelo exercício. As setas indicam regulação UR ( $\uparrow$ ) ou DR ( $\downarrow$ ). Os números apresentam o FC. (Figura produzida pelos autores). 


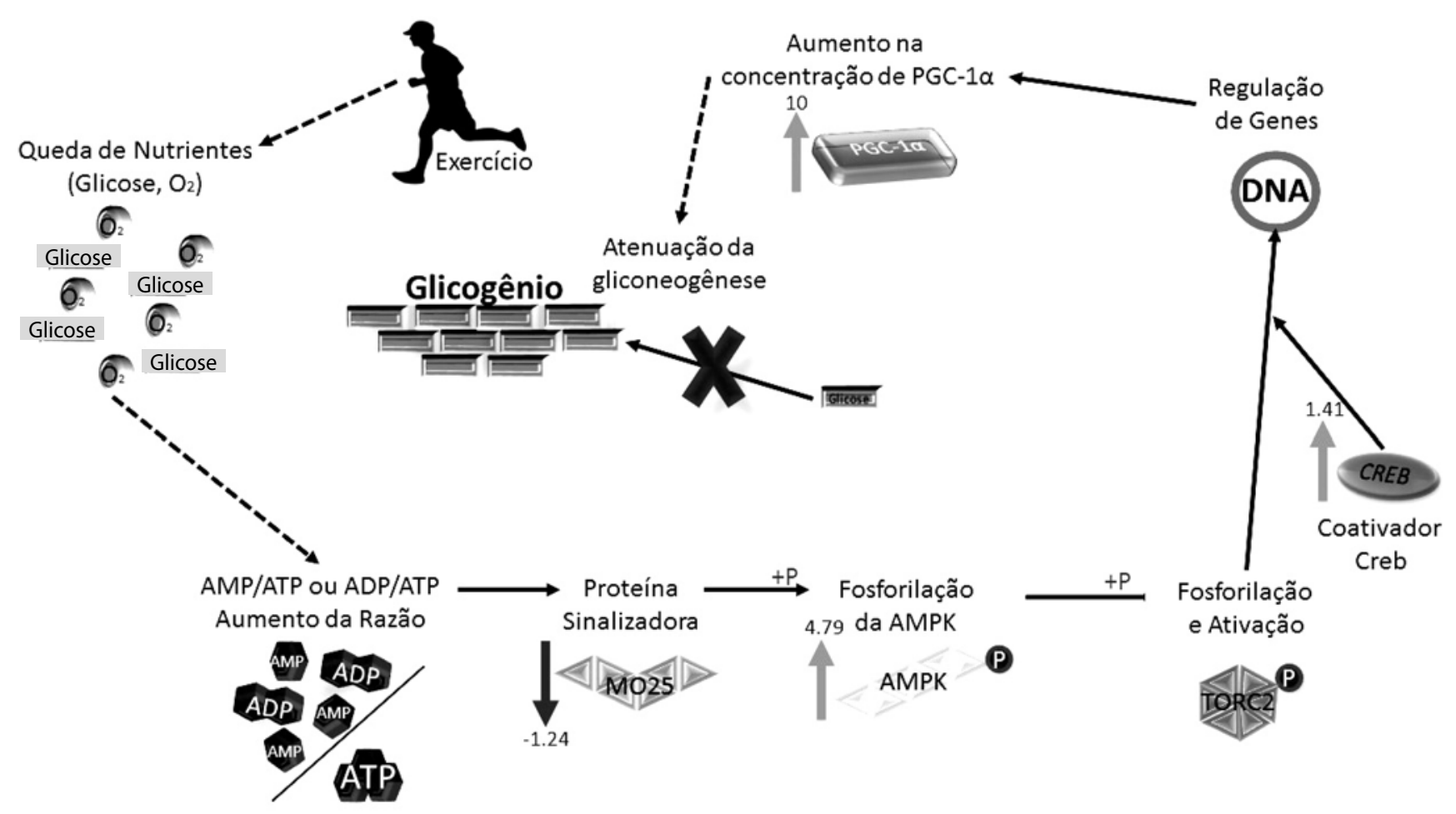

Figura 2. Rota de ativação da biogênese mitocondrial pelo exercício. As setas indicam regulação UR ( $\uparrow$ ) ou DR ( $\downarrow$ ). Os números apresentam o FC. (Figura produzida pelos autores).

\section{RESULTADOS}

Este trabalho buscou uma caracterização gênica, de natureza a posteriori, da via AMPK e sua regulação pelo exercício físico, via revisão sistemática, seguida de análise in silico. Dos 65 genes encontrados (Tabela 1) obtidos na interface da revisão sistemática x via do repositório KEGG, 17 genes mostraram UR e 24 mostraram DR, em relação ao seu respectivo controle. Além destes, 20 genes estavam presentes nos trabalhos, apresentando tanto UR e DR e quatro genes não apresentaram dados de regulação. Portanto, dos 133 genes da via AMPK, 48,8\% dela foi amostrada nos trabalhos revisados indicando que uma parte significativa da via sofre regulação pelo exercício.

Em termos de tipo de exercício efetuado no trabalho, o número de genes que foram amostrados no exercício de endurance foram 35 e de genes com trabalho de força ou exercício resistido foram 17 genes. Genes da via AMPK que foram amostrados nos dois tipos de exercício totalizaram 11 genes. Dois genes não tiveram tipo de exercício associado.

Os maiores FCs encontrados pertenceram ao gene PPARGC1A (Peroxisome proliferator-activated receptor gamma, coactivator 1 alpha), no valor de 10 vezes o valor encontrado no seu controle, tanto em exercício de endurance quanto resistido. O gene SCD (Stearoyl-CoA desaturase (delta-9-desaturase)) também teve sua expressão fortemente induzida pelo exercício de endurance, com um valor de FC de 4,79. Outros genes UR foram PRKAG2, CCND1 e IRS2.

\section{DISCUSSÃO}

Após o estímulo do exercício físico, o fator PGC-1á pode ser regulado positivamente ou negativamente, como visto na maioria dos estudos encontrados na Tabela 1, na qual dos onze trabalhos, em dez a expressão do gene PPARGC1A, que codifica o fator PGC-1a, é regulada positivamente. De fato, o fator PGC-1a é um modulador transcricional dos genes reguladores do metabolismo energético e da proteína GLUT 4, responsável pelo transporte de glicose na membrana celular, regulada pela insulina.Esse processo leva a um aumento da atividade da biogênese mitocondrial ${ }^{32}$ (Figura 2).
O exercício resistido induz a atividade da via PI3-K/Akt/mTOR sinalizadora da cascata de modulação da síntese protéica e, portanto, causadora da hipertrofia. Apesar de poucos genes, temos alguns indícios de ativação pelo exercício especialmente do gene AKT3, o qual mostrou FC com valor positivo, UR de 1,5; além da forte ligação dos referidos genes à via mTOR.

O trabalho de Liu et al. ${ }^{9}$, foi feito exclusivamente em mulheres. Os dados de expressão apresentados neste trabalho mostraram uma regulação DR dos genes da via mTOR. Os autores consideraram este fato como especificamente um caso de gênero, em que a repressão coordenada de reguladores negativos da via de sinalização da mTOR não foi observada. Segundo os autores, estes dados necessitam ser elucidados para esclarecer o dimorfismo sexual nos fenótipos musculares.

No exercício de endurance, a via sinalizadora da AMPK mostrou alta ligação dos genes a esta via. No caso da via mTOR temos também uma alta vinculação, porém de somente sete genes. O trabalho de Lindholm et al. ${ }^{22}$, não faz menção a via AMPK ou mTOR.

A seguir apresentamos duas rotas metabólicas da via da AMPK afetadas pelo déficit energético causado pelo exercício, estabelecendo a ligação delas com a regulação positiva e negativa dentro das rotas metabólicas.

A biogênese mitocondrial é um processo complexo, tendo em vista que é composta por produtos gênicos e resposta coordenada de ambos genomas nuclear e mitocondrial para manutenção do arranjo de proteínas durante a síntese de organelas. Esta reposta coordenada é alcançada por uma grande variedade de fatores de transcrição e coativadores transcricionais ${ }^{33,34}$.

Com o estudo da via de sinalização da AMPK pelo exercício foi possível observar algumas vias de ativação do fator PGC-1a (Figura 1). Em um deles, o exercício leva a uma defasagem de nutrientes celulares como glicose e oxigênio e aumento da razão entre AMP/ATP. Esse comportamento suprime a síntese da proteína $\mathrm{MO} 25$, que atua na transdução de sinal processando informações ambientais. A supressão dessa proteína 
indica que essa defasagem é gerada por algo externo, assim a proteína AMPK é ativada. Essa proteína é uma quinase que é ativada pelo excesso de AMP indicado pela ausência da proteína MO25.

Os genes CAB39 e CAB39L vistos na Tabela 1 são componentes de um complexo que se liga e ativa STK1/LKB1. No complexo é requerida para a estabilização da interação dos complexos CAB39/MO25 (CAB39/ MO25alpha ou CAB39L/MO25beta) e STK11/LKB135. A proteína kinase dependente de cálcio/calmodulina II (CaMK2) (Tabela 1) é um importante sinalizador para a receptação de glicose após uma sessão aguda de exercício aeróbico ${ }^{35}$.

Possíveis reguladores da PGC-1a, alguns genes possivelmente ligados a regulação positiva, SIRT1, causam desacetilação pós-traducional, AMPK e a proteína CaMK2 (Tabela 1). Estudos revelaram que a proteína CaMK2 ativa as vias de sinalização da AMPK em resposta ao exercício aeróbico ${ }^{36,37}$, porém outros estudos mostraram que a CaMK2 pode gerar um aumento na absorção de glicose sem ativar a via de sinalização da $\mathrm{AMPK}^{38,39}$. Após uma sessão aguda de exercício de resistência tanto AMPK quanto a CaMK2 se encontram fosforiladas, o que pode contribuir para receptação da glicose ${ }^{39,40}$. No entanto, nenhum estudo demonstrou o papel da AMPK e da CaMK2 na receptação de glicose induzida pelo exercício de resistência. A fosforilação de TBC1D1 e AS160 ocorre distante de AMPK e CaMK2, estas fosforilações aumentam a translocação de GLUT 4 e dessa forma, aumentam a recaptação de glicose $\mathrm{e}^{39,41}$

Recentemente, co-repressores nucleares como RIP140 (corepressor receptor-interacting protein 140), NCor (nuclear corepressor) e SMRT (silencing mediator of retinoid and thyroid hormone receptors) foram inseridos como reguladores do processo. $O$ antagonismo direto entre PG-1a e RIP140 reduz a oxidação de ácidos graxos e de piruvato. NCor é um co-repressor de NRs (Nuclear Respiratoryfactors) e de PGC-1a e seu antagonismo controla a sensibilidade a insulina em tecidos metabólicos. SMRT é requerido para a sensibilidade a insulina pelo adipócito e também é parceiro do fator NCor quando este é recrutado pelos fatores $\mathrm{Nrs}^{42}$.

\section{Gliconeogênese}

Outro ramo da via de sinalização via AMPK pelo exercício, a gliconeogênese (Figura 2), apresenta também uma sinalização após uma queda de glicose e Oxigênio, onde ocorre uma regulação negativa dos genes codificadores da proteína M025. A supressão da produção dessa proteína informa a defasagem causada por algo externo, como na via anterior, isso leva a uma regulação positiva dos genes codificadores da proteína AMPK. Esse comportamento leva a fosforilação da proteína TORC2, ativando essa proteína.

A proteína TORC2 regula o coativador CREB e essas proteínas funcionam juntas e atuam no DNA aumentando a produção de PGC-1a. Esse mecanismo inibe a gliconeogênese e aumenta a disponibilidade de glicose. $\mathrm{O}$ detalhe da via é que a proteína PGC-1 a possui regulação positiva e negativa, porém apenas um estudo apresenta uma regulação negativa, possuindo uma variação negativa de 1,01, a qual é bem pequena em comparação aos outros estudos que apresentam variações positivas de 1,12 a 1015,16,18,20.

\section{CONCLUSÃO}

Este trabalho mostrou que o exercício físico atua ativamente na via de sinalização da AMPK, regulando a expressão de mais da metade de genes, avaliados por técnicas inovadoras. Verificou-se a possível regulação específica em função do tipo de exercício efetuado, porém poucos genes foram especificamente avaliados, especialmente para o exercício resistido. O trabalho apresentou a regulação gênica de dois mecanismos para a recuperação energética, a biogênese mitocondrial e o bloqueio da gliconeogênese.

\section{AGRADECIMENTOS}

Os autores agradecem as agências de fomento FUNCAP, CNPq e CAPES pelo apoio financeiro.

Todos os autores declararam não haver qualquer potencial conflito de interesses referente a este artigo.

CONTRIBUIÇÕES DOS AUTORES: Cada autor contribuiu individual e significativamente para o desenvolvimento do manuscrito. CP (0000-0003-1829-1515)* realizou a revisão sistemática, aquisição e tabulação dos dados, análises de bioinformática e redação. LHPS (0000-0003-1296-7596)* contribuiu com a aquisição e tabulação dos dados, e redação. JOA (0000-0003-2230-4614)* contribuiu na aquisição e tabulação dos dados, revisão. ANQ (0000-0002-3238-6521)* e PMS (0000-0002-3592-4444)* participaram do desenho do experimento e revisão. VMC (0000-0003-4839-4400)* contribuiu no desenho do experimento, análises de bioinformática, redação. *ORCID (Open Researcher and Contributor ID).

\section{REFERÊNCIAS}

1. Trapnell C, Roberts A, Goff L, Pertea G, Kim D, Kelley DR, et al. Differential gene and transcript expression analysis of RNA-seq experiments with TopHat and Cufflinks. Nat Protoc. 2012;7(3):562-78.

2. Park KD, Park J, Ko J, Kim BC, Kim HS, Ahn K, et al. Whole transcriptome analyses of six thoroughbred horses before and after exercise using RNA-Seq. BMC Genomics. 2012;13:473.

3. Bustin SA, Benes V, Garson JA, Hellemans J, Huggett J, Kubista M, et al. The MIQE guidelines: minimum information for publication of quantitative real-time PCR experiments. Clin Chem. 2009;55(4):611-22.

4. Mortazavi A, Williams BA, McCue K, Schaeffer L, Wold B. Mapping and quantifying mammalian transcriptomes by RNA-Seq. Nat Methods. 2008;5(7):621-8.

5. Auer PL, Doerge RW. Statistical design and analysis of RNA sequencing data. Genetics. 2010;185(2):405-16.

6. Allison DB, Cui X, Page GP, Sabripour M. Microarray data analysis: from disarray to consolidation and consensus. Nat Rev Genet. 2006;7(1):55-65.

7. Bouchard C. Exercise genomics--a paradigm shift is needed: a commentary. Br J Sports Med. 2015;49(23):1492-6.

8. Kido K, Ato S, Yokokawa T, Makanae Y, Sato K, Fujita S. Acute resistance exercise-induced IGF1 expression and subsequent GLUT4 translocation. Physiol Rep. 2016;4(16).pii: e12907.

9. Liu D, Sartor MA, Nader GA, Gutmann L, Treutelaar MK, Pistilli EE, et al. Skeletal muscle gene expression in response to resistance exercise: sex specific regulation. BMC Genomics. 2010;11:659.

10. Bolster DR, Crozier SJ, Kimball SR, Jefferson LS. AMP-activated protein kinase suppresses protein synthesis in rat skeletal muscle through down-regulated mammalian target of rapamycin (mTOR) signaling. J Biol Chem. 2002;277(27):23977-80

11. Bergeron R, Previs SF, Cline GW, Perret P, Russell RR 3rd, Young LH, et al. Effect of 5-aminoimidazole4-carboxamide-1-beta-D-ribofuranoside infusion on in vivo glucose and lipid metabolism in lean and obese Zucker rats. Diabetes. 2001;50(5):1076-82

12. McGee SL, van Denderen BJ, Howlett KF, Mollica J, Schertzer JD, Kemp BE, et al. AMP-activated protein kinase regulates GLUT4 transcription by phosphorylating histone deacetylase 5. Diabetes. 2008;57(4):860-7.

13. Pacheco C, Felipe SM, Soares MM, Alves JO, Soares PM, Leal-Cardoso JH, et al. A compendium of physical exercise-related human genes: an 'omic scale analysis. Biol Sport. [In press].

14. Kanehisa M, Goto S, Sato Y, Furumichi M, Tanabe M. KEGG for integration and interpretation of large-scale molecular data sets. Nucleic Acids Res. 2012;40(Database issue):D109-14.

15. Bray MS, Hagberg JM, Pérusse L, Rankinen T, Roth SM, Wolfarth B, et al. The human gene map for performance and health-related fitness phenotypes: the 2006-2007 update. Med Sci Sports Exerc. 2009;41(1):35-73

16. Psilander N, Wang L, Westergren J, Tonkonogi M, Sahlin K. Mitochondrial gene expression in elite cyclists: effects of high-intensity interval exercise. Eur J Appl Physiol. 2010;110(3):597-606.

17. Pilegaard $H$, Saltin $B$, Neufer PD. Exercise induces transient transcriptional activation of the PGC-1 a gene in human skeletal muscle. J Physiol. 2003;546(Pt 3):851-8.

18. Egan B, Zierath JR. Exercise metabolism and the molecular regulation of skeletal muscle adaptation. Cell Metab. 2013;17(2):162-84

19. Gibala MJ, McGee SL, Garnham AP, Howlett KF, Snow RJ, Hargreaves M. Brief intense interval exercise activates AMPK and p38 MAPK signaling and increases the expression of PGC-1alpha in human skeletal muscle. J Appl Physiol (1985). 2009;106(3):929-34.

20. Popov D, Zinovkin R, Karger E, Tarasova O, Vinogradova O. Effects of continuous and intermittent aerobic exercise upon mRNA expression of metabolic genes in human skeletal muscle. J Sports Med Phys Fitness. 2014;54(3):362-9. 
21. Timmons JA, Knudsen S, Rankinen T, Koch LG, Sarzynski M, Jensen T, et al. Using molecular classification to predict gains in maximal aerobic capacity following endurance exercise training in humans. J Appl Physiol (1985). 2010;108(6):1487-96

22. Lindholm ME, Marabita F, Gomez-Cabrero D, Rundqvist H, Ekström TJ, Tegnér J, et al. An integrative analysis reveals coordinated reprogramming of the epigenome and the transcriptome in human skeletal muscle after training. Epigenetics. 2014;9(12):1557-69.

23. Stepto NK, Coffey VG, Carey, et al. Global gene expression in skeletal muscle from well-trained strength and endurance athletes. Med Sci Sports Exerc. 2009;41(3):546-5

24. Ruchat SM, Rankinen T, Weisnagel SJ, Rice T, Rao DC, Bergman RN, et al. Improvements in glucose homeostasis in response to regular exercise are influenced by the PPARG Pro12Ala variant: results from the HERITAGE Family Study. Diabetologia. 2009;53(4):679-9.

25. Walsh S, Haddad CJ, Kostek MA, Angelopoulos TJ, Clarkson PM, Gordon PM, et al. Leptin and leptin receptor genetic variants associate with habitual physical activity and the arm body composition response to resistance training. Gene. 2012;510(1):66-70

26. Golbidi S, Laher I. Exercise induced adipokine changes and the metabolic syndrome. J Diabetes Res. 2014;2014:726861.

27. Moran CN, Barwell ND, Malkova D, Cleland SJ, MCPhee I, Packard CJ, et al. Effects of diabetes family history and exercise training on the expression of adiponectin and leptin and their receptors. Metabolism. 2011;60(2):206-4

28. Kraemer, RR, Castracane VD. Exercise and humoral mediators of peripheral energy balance: ghrelin and adiponectin. Exp Biol Med (Maywood). 2007;232(2):184-94.

29. De Moor MHM, Liu YJ, Boomsma DI, Li J, Hamilton JJ, Hottenga JJ, et al. Genome-wide Association Study of Exercise Behavior in Dutch and American Adults. MedSci Sports Exerc. 2009;41(10):1887-95.

30. Radom-Aizik S, Zaldivar F, Haddad F, Cooper DM. Impact of brief exercise on peripheral blood NK cell gene and microRNA expression in young adults. J Appl Physiol (1985). 2013;114(5):628-36.

31. Szklarczyk D, Franceschini A, Wyder S, Forslund K, Heller D, Huerta-Cepas J, et al. STRING v10: protein-protein interaction networks, integrated over the tree of life. Nucleic Acids Res. 2015;43(Database issue):D447-52.
32. Olesen J, Kiilerich K, Pilegaard H. PGC-1alpha-mediated adaptations in skeletal muscle. Pflugers Arch. 2010;460(1):153-62

33. Hood DA. Invited Review: contractile activity-induced mitochondrial biogenesis in skeletal muscle. J Appl Physiol (1985). 2001;90(3):1137-57.

34. Adhihetty PJ, Ljubicic V, Menzies KJ, Hood DA. Differential susceptibility of subsarcolemmal and intermyofibrillar mitochondria to apoptotic stimuli. Am J Physiol Cell Physiol. 2005;289(4):C994-C1001.

35. Zeqiraj E, Filippi BM, Deak M, Alessi DR, van Aalten DM. Structure of the LKB1-STRAD-MO25 complex reveals an allosteric mechanism of kinase activation. Science. 2009;326(5960):1707-11.

36. Raney MA, Turcotte LP. Evidence for the involvement of CaMKIl and AMPK in Ca2+-dependent signaling pathways regulating FA uptake and oxidation in contracting rodent muscle. J Appl Physiol (1985) 2008;104(5):1366-73.

37. Morales-Alamo D, Ponce-González JG, Guadalupe-Grau A, Rodríguez-García L, Santana A, Cusso R, et al. Critical role for free radicals on sprint exercise-induced CaMKIl and AMPKa phosphorylation in human skeletal muscle. J Appl Physiol (1985). 2013;114(5):566-77.

38. Pfisterer SG, Mauthe M, Codogno P, Proikas-Cezanne T. Ca2+/calmodulin-dependent kinase (CaMK) signaling via CaMKI and AMP-activated protein kinase contributes to the regulation of WIPI-1 at the onset of autophagy. Mol Pharmacol. 2011;80(6):1066-75.

39. Witczak CA, Jessen N, Warro DM, Toyoda T, Fujii N, Anderson ME, et al. CaMKIl regulates contractionbut not insulin-induced glucose uptake in mouse skeletal muscle. Am J Physiol Endocrinol Metab. 2010;298(6):E1150-60

40. Ogasawara R, Nakazato K, Sato K, Boppart MD, Fujita S. Resistance exercise increases active MMP and B1-integrin protein expression in skeletal muscle. Physiol Rep. 2014;2(11).pii:e12212.

41. Chavez JA, Roach WG, Keller SR, Lane WS, Lienhard GE. Inhibition of GLUT4 translocation by Tbc1d1, a Rab GTPase-activating protein abundant in skeletal muscle, is partially relieved by AMP-activated protein kinase activation. J Biol Chem. 2008;283(14):9187-95.

42. Qi Z, Ding S. Transcriptional Regulation by Nuclear Corepressors and PGC-1a: Implications for Mitochondrial Quality Control and Insulin Sensitivity. PPAR Res. 2012;2012:348245. 